\title{
INVESTIGATION OF THE EFFECTS OF STARTING pH, MASS AND RETENTION TIME ON BIOGAS PRODUCTION USING POULTRY DROPPINGS AS FEEDSTOCK
}

\author{
O. A. Adebimpe ${ }^{1, *}$, I. E. Edem ${ }^{2}$ and O. L. Ayodele ${ }^{3}$ \\ $\mathbf{1 , 2 , 3}$ Dept of Industrial ANd Production ENGR'G, UniVersity OF IBADAN, IBADAN, OYo STATE, NIGERIA \\ E-mail addresses: ${ }^{1}$ oa.adebimpe@mail1.ui.edu.ng, ${ }^{2}$ ie.edem@mail1.ui.edu.ng, \\ 3ayodele.tosin99@gmail.com
}

\begin{abstract}
The effect of starting $\mathrm{pH}$, mass and retention time on biogas production was studied using poultry droppings as the feedstock. A full factorial experiment was designed and performed with starting pH set at 5, 6, 7, 8 \& 9 for feedstock mass of $100 \mathrm{~g}$ and $200 \mathrm{~g}$ at specific retention times. The results presented an optimal biogas yield at $\mathrm{pH}=7$ with a volume of 722 and $1046 \mathrm{~cm}^{3}$ while $\mathrm{pH}=5$ had the least with 255 and $481 \mathrm{~cm}^{3}$ at $100 \mathrm{~g}$ and $200 \mathrm{~g}$ mass respectively. The starting $\mathrm{pH}$, mass and retention time and the interaction of starting $\mathrm{pH}$ and mass had significant effect on biogas yield at $5 \%$ significance level. The $R$-Square value obtained from the analysis was $92.1 \%$. Thereafter, a loglinear regression model for predicting biogas yield was generated and was found to provide adequate prediction given its MAPE value of 19.97.
\end{abstract}

Keywords: Biogas Production, Mass, Poultry Droppings, Retention Time, Starting pH.

\section{INTRODUCTION}

Increasing energy need, population growth, declining fossil fuels and the environmental issues that surround the use of fossil fuels has led to an increasing interest in clean alternative sources of energy. According to Weiland [1], fossil fuel usage has significantly contributed to the level of Carbon (IV) Oxide $\left(\mathrm{CO}_{2}\right)$ emissions and greenhouse gases (GHGs). In order to curb the numerous problems associated with the use of fossil fuels, research is tilting towards renewable energy sources such as, solar, wind and biomass [23]. Also, renewable energy sources are affordable and environment-friendly [4-6].

Among the renewable energy sources, biogas energy has received much interest in recent times [7]. This is as a result of its applicability in small and large scale energy generation [8]. Also, its beneficial waste management and environmental preservation characteristics has further encouraged its adoption [910].

Biogas can be generated from wastes, energy crops and animal faeces. Biogas constituents are primarily methane and $\mathrm{CO}_{2}$ and are suitable for heat and power production [11-12]. According to Bharathiraja et al.; Haryanto et al. [13-14], agricultural residues such as, livestock faeces, residues and wastes from food industries are the most suitable substrates for biogas production. They are readily available, environment friendly and have economic values. However, other technical parameters that are vital to biogas production exists. Such include, concentration, temperature, $\mathrm{pH}$, hydraulic retention time and reactor configuration [15-16].

The production of biogas, involves a biological conversion of biomass into biogas by microorganisms in the absence of oxygen [17]. This is a proven method and is referred to as Anaerobic Digestion (AD) [13]. It is an efficient and a beneficial method for biodegradation, biofuel production and sustainable waste management of waste [13;18-20]. However, the operation performance of $A D$ which is measured based on the biogas yield is dependent on factors such as the concentration, temperature, mass etc. Thus, to achieve maximum biogas yield from a substrate, it is necessary to know the appropriate settings and the

* Corresponding author, tel: +234 805-671-5624 
point at which these technical parameters aid optimal biogas yield.

Previous research has considered the influence of various feedstock on biogas yield. Such as, agricultural wastes, food wastes and spoilt milk [21-23]. In Belostotskiy et al. [24], the effect of anaerobic digestion of chicken manure as a single substrate in biogas production was investigated with the organic loading rate as the main factor considered. The loading was done alongside the use controlled ammonia concentration to reduce the amount of inhibiting ammonia in the process. The results gave an insight into the potential of chicken manure as a suitable substrate. Kim [25] investigated the influence of temperature and hydraulic retention time on anaerobic digestion of food waste. It was concluded that more biogas yield is obtained at increased thermophilic temperature than at mesophilic. Budiyono [26] studied the effect of substrate concentration on biogas production using cattle manure with rumen fluid as inoculum. Dennis [17], also performed similar experiment and introduced inoculums into cattle manure to observe the effect on biogas yield. The result showed that increase inoculums resulted into increase in biogas production. Raheman and Mondal [27] investigated the solid concentration of a Jatropha in biogas production. Kafle et al. [28] studied the effects of co-digestion using waste silage and swine waste at mesophilic temperatures. Jayaraj et al.; Deepanraj et al. [29-30] studied the effect of $\mathrm{pH}$ and temperature respectively on biogas production with food waste as the substrate. However, the review showed that there are limited works on the effects of starting $\mathrm{pH}$, the mass of substrate, retention time and their contributory effects in biogas yield. These three technical parameters are yet to be dealt with exhaustively. Thus, this has become the aim of this research. The research is to investigate the individual and contributory effects of the three technical parameters on biogas production from poultry droppings.

\section{METHODOLOGY}

\subsection{Substrate Sourcing, Collection and Design of Experiment}

Poultry droppings were sourced from the teaching and research farm of a University located in the south-west of Nigeria. Following this, the experiment was designed using three factors namely; starting $\mathrm{pH}$, mass and retention time at a mixed level of 5, 2, and 10 respectively. A full factorial experimental design was created. The experiments were thereafter carried out within the laboratory using the necessary equipment and a feedstock size.

The designed experiments were carried out on the basis of the following Null $\left(H_{0 i}\right)$ and alternative $\left(H_{1 i}\right)$ hypotheses:

1. $H_{o 1}$ : There is no significant main effect of the starting $\mathrm{pH}$ on biogas yield

2. $H_{11}$ : There is a significant main effect of the starting $\mathrm{pH}$ on biogas yield.

3. $H_{o 2}$ : There is no significant main effect of the mass of substrate on the biogas yield

4. $H_{12}$ : There is a significant main effect of the mass of substrate on the biogas yield

5. $H_{o 3}$ : There is no significant main effect of retention time on the biogas yield

6. $H_{13}$ : There is a significant main effect of retention time on the biogas yield

7. $H_{04}$ : There is no effect of the interaction between $\mathrm{pH}$ and mass on the yield of biogas

8. $H_{14}$ : There is an effect of the interaction between $\mathrm{pH}$ and mass on the yield of biogas

9. $H_{05}$ : There is no effect of the interaction between $\mathrm{pH}$ and retention time on the yield of biogas

10. $H_{15}$ : There is an effect of the interaction between $\mathrm{pH}$ and retention time on the yield of biogas

11. $H_{o 6}$ : There is no effect of the interaction between mass and retention time on the yield of biogas

12. $H_{16}$ : There is an effect of the interaction between mass and retention time on the yield of biogas

13. $H_{07}$ : There is no effect of the interaction between $\mathrm{pH}$, mass and retention time on the yield of biogas

14. $H_{17}$ : There is an effect of the interaction between $\mathrm{pH}$, mass and retention time on the yield of biogas

At a $p$-value of less than $0.05, H_{0 i}$ was rejected and $H_{1 i}$ accepted, otherwise $H_{0 i}$ was accepted.

\subsection{Experimental setup \\ 2.2.1. Apparatus}

The following apparatus were used for the experiment: measuring cylinders, mini-sized airtight digesters fabricated from plastic materials fitted with rubber tubes to avoid biogas leakage, thermometer, weighing balance, $\mathrm{pH}$ meter, tetraoxosulphate (VI) 
acid $\left(\mathrm{H}_{2} \mathrm{SO}_{4}\right)$ and Sodium Hydroxide $(\mathrm{NaOH})$ solutions of 0.1 Molar concentration, retort stands and clamps.

\subsubsection{Experimental Procedure}

Firstly, a sample of the sourced poultry droppings was analysed to establish its Dry matter (DM) content. This was achieved by oven-drying a dry sample of the substrate at $105^{\circ} \mathrm{C}$ for 15 hours. The DM content of the substrate was subsequently determined by weighing and checking the substrate weight before and after the drying process. This was done to ensure that the DM content of the substrate did not exceed the maximum recommended amount [31].

Ten runs of the experiment made up of one hundred observation windows were carried out in two replicates. In each run, the poultry droppings was measured into $100 \mathrm{~g}$ and $200 \mathrm{~g}$ using weighing balance. The droppings were then converted into its substrate form by dilution in water $(100 \mathrm{~g}$ and $200 \mathrm{~g}$ were diluted with $100 \mathrm{~cm}^{3}$ and $200 \mathrm{~cm}^{3}$ respectively) and fed into a digester. A tube from the fitted digester was inserted into clamped water filled inverted cylinders and placed in the water bath. The $\mathrm{pH}$ meter was subsequently used to measure the initial $\mathrm{pH}$ of the sample. Using the $\mathrm{H}_{2} \mathrm{SO}_{4}$ or $\mathrm{NaOH}$ solutions, the sample was then conditioned to various starting pH levels $(5,6,7,8$ and 9) substrate $\mathrm{pH}$ level. The runs of the experiment were observed on a 24-hour window of increasing retention time. The mesophilic temperature range $\left(26^{0} \mathrm{C}-32^{\circ} \mathrm{C}\right)$ was employed for carrying out the experiment. Each run of the experiment was terminated at the tenth period from the first observation window. Once the desired retention time for a run was attained, the experiment was terminated for that run. The cumulative volume of biogas yield was measured and recorded for each observation window one day after the substrate had been charged. The method of biogas collection used was the downward displacement of water technique. The retention time during each observation window was also recorded. At the maximum retention time for each run, the terminating $\mathrm{pH}$ was also measured and recorded.

A factorial design worksheet was used for recording the experiment design details and all necessary information obtained in the course of carrying out the experiment. The analysis of the resulting data was subsequently undertaken by the use of the StatRegression-Regression tab of the software package; MINITAB 16. The daily and cumulative biogas yield for behaviour $i$ run $Y_{i}$, was theorized to follow a loglinear relationship as expressed in equation (1).

$$
\begin{array}{r}
\operatorname{Ln}\left(Y_{i}\right)=X_{1 i}+X_{2 i}+X_{3 i}+X_{1 i}^{2}+X_{1 i} X_{2 i}+X_{1 i} X_{3 i}+X_{2 i}^{2} \\
+X_{2 i} X_{3 i}+X_{3 i}^{2}+X_{1 i}^{3}+X_{1 i}^{2} X_{2}+X_{1 i}^{2} X_{3 i} \\
X_{1 i} X_{2 i}^{2}+X_{1 i} X_{3 i}^{2}+X_{2 i}^{3}+X_{2 i}^{2} X_{3 i}+X_{3 i}^{3}+X_{1 i} X_{2 i} X_{3 i}
\end{array}
$$

Where: $X_{1 i}, X_{2 i}, X_{3 i}$ the values of $\mathrm{pH}$, mass and retention time for each run $i(i=1,2,3, \ldots, 100)$.

The yield residual plots, as well as the regression analysis results from the software, were employed to determine the factors which exhibited main and interacting effects on the biogas yield. The index of the significance of the effect of the factors ( $p$-value) was set at $p \leq 0.05$ such that effects and interactions which fell within this region were accepted and presented as a reduced form of the relation $\left(\operatorname{Ln}\left\{Y_{i}\right\}\right)^{R}$ while those which fell outside were rejected. In order to obtain a better grasp of the model's prediction precision, the Mean Absolute Percentage Error (MAPE) was subsequently employed in determining the accuracy of the non-logarithmic predictions from $Y_{i}^{R}$ using equation (2)

$$
\delta=\sum_{i=1}^{i=n} 100\left\{\frac{\left\{Y_{i}^{a}-Y_{i}^{R} \mid\right.}{Y_{i}^{a}}\right\}
$$

Where;

$$
Y_{i}^{R}=\operatorname{Exp}\left(\ln \left\{Y_{i}^{R}\right\}\right)
$$

Where $\delta$ : MAPE of the model prediction, $Y_{i}^{a}$ : Experimental value of biogas yield at run $i(i=$ $1,2,3 \ldots n\{n \leq 100\})$

\section{RESULTS AND DISCUSSION}

The DM content of the substrate was found to be $39.26 \%$. This indicated that the fresh poultry droppings used was a suitable feedstock for the generation of biogas [31]. Table 1 shows a part of the factorial design worksheet contents including the independent and response factors as well as the terminating $\mathrm{pH}$ for each experimental run. The daily biogas yield of the poultry droppings obtained at various $\mathrm{pH}$ conditions within the retention time studied is shown in Figures 1 and 2.

Table 1: Biogas yield results based on effective experimental runs carried out

\begin{tabular}{clllll}
\multicolumn{6}{c}{ experimental runs carried out } \\
\hline S/N & $\begin{array}{l}\text { Mass } \\
(\mathbf{g})\end{array}$ & $\begin{array}{l}\text { Starting } \\
\text { pH }\end{array}$ & $\begin{array}{l}\text { Residence } \\
\text { time (days) }\end{array}$ & $\begin{array}{l}\text { Cumulative } \\
\text { Yield }\left(\mathbf{c m}^{3}\right)\end{array}$ & $\begin{array}{l}\text { Terminating } \\
\text { PH }\end{array}$ \\
\hline $1^{*}$ & 100 & 5 & 1 & 0 & 5.6 \\
2 & 100 & 5 & 2 & 9 & \\
3 & 100 & 5 & 3 & 63 &
\end{tabular}




\begin{tabular}{|c|c|c|c|c|c|}
\hline$S / N$ & $\begin{array}{l}\text { Mass } \\
\text { (g) }\end{array}$ & $\begin{array}{l}\text { Starting } \\
\mathrm{pH}\end{array}$ & $\begin{array}{l}\text { Residence } \\
\text { time (days) }\end{array}$ & $\begin{array}{l}\text { Cumulative } \\
\text { Yield }\left(\mathrm{cm}^{3}\right)\end{array}$ & $\begin{array}{l}\text { Terminating } \\
\mathrm{PH}\end{array}$ \\
\hline 4 & 100 & 5 & 4 & 107 & \\
\hline 5 & 100 & 5 & 5 & 142 & \\
\hline 6 & 100 & 5 & 6 & 180 & \\
\hline 7 & 100 & 5 & 7 & 203 & \\
\hline 8 & 100 & 5 & 8 & 218 & \\
\hline 9 & 100 & 5 & 9 & 235 & \\
\hline 10 & 100 & 5 & 10 & 255 & \\
\hline $11^{*}$ & 100 & 6 & 1 & 0 & 6.2 \\
\hline 12 & 100 & 6 & 2 & 25 & \\
\hline 13 & 100 & 6 & 3 & 109 & \\
\hline 14 & 100 & 6 & 4 & 187 & \\
\hline 15 & 100 & 6 & 5 & 247 & \\
\hline 16 & 100 & 6 & 6 & 294 & \\
\hline 17 & 100 & 6 & 7 & 327 & \\
\hline 18 & 100 & 6 & 8 & 364 & \\
\hline 19 & 100 & 6 & 9 & 392 & \\
\hline 20 & 100 & 6 & 10 & 417 & 5.9 \\
\hline $21^{*}$ & 100 & 7 & 1 & 8 & \\
\hline 22 & 100 & 7 & 2 & 73 & \\
\hline 23 & 100 & 7 & 3 & 233 & \\
\hline 24 & 100 & 7 & 4 & 339 & \\
\hline 25 & 100 & 7 & 5 & 428 & \\
\hline 26 & 100 & 7 & 6 & 501 & \\
\hline 27 & 100 & 7 & 7 & 563 & \\
\hline 28 & 100 & 7 & 8 & 632 & \\
\hline 29 & 100 & 7 & 9 & 675 & \\
\hline 30 & 100 & 7 & 10 & 722 & 6.7 \\
\hline $31^{*}$ & 100 & 8 & 1 & 2 & \\
\hline 32 & 100 & 8 & 2 & 62 & \\
\hline 33 & 100 & 8 & 3 & 202 & \\
\hline 34 & 100 & 8 & 4 & 299 & \\
\hline 35 & 100 & 8 & 5 & 383 & \\
\hline 36 & 100 & 8 & 6 & 458 & \\
\hline 37 & 100 & 8 & 7 & 508 & \\
\hline 38 & 100 & 8 & 8 & 564 & \\
\hline 39 & 100 & 8 & 9 & 604 & \\
\hline 40 & 100 & 8 & 10 & 640 & 7.5 \\
\hline $41^{*}$ & 100 & 9 & 1 & 0 & \\
\hline 42 & 100 & 9 & 2 & 25 & \\
\hline 43 & 100 & 9 & 3 & 85 & \\
\hline 44 & 100 & 9 & 4 & 139 & \\
\hline 45 & 100 & 9 & 5 & 194 & \\
\hline 46 & 100 & 9 & 6 & 234 & \\
\hline 47 & 100 & 9 & 7 & 262 & \\
\hline 48 & 100 & 9 & 8 & 294 & \\
\hline 49 & 100 & 9 & 9 & 324 & \\
\hline 50 & 100 & 9 & 10 & 346 & 8.2 \\
\hline $51^{*}$ & 200 & 5 & 1 & 9 & \\
\hline 52 & 200 & 5 & 2 & 46 & \\
\hline 53 & 200 & 5 & 3 & 112 & \\
\hline
\end{tabular}

\begin{tabular}{llllll}
\hline S/N & $\begin{array}{l}\text { Mass } \\
(\mathbf{g})\end{array}$ & $\begin{array}{l}\text { Starting } \\
\mathbf{p H}\end{array}$ & $\begin{array}{l}\text { Residence } \\
\text { time (days) }\end{array}$ & $\begin{array}{l}\text { Cumulative } \\
\text { Yield }\left(\mathbf{c m}^{\mathbf{3}}\right)\end{array}$ & $\begin{array}{l}\text { Terminating } \\
\mathbf{P H}\end{array}$ \\
\hline 54 & 200 & 5 & 4 & 185 & \\
55 & 200 & 5 & 5 & 247 & \\
56 & 200 & 5 & 6 & 316 & \\
57 & 200 & 5 & 7 & 358 & \\
58 & 200 & 5 & 8 & 396 & \\
59 & 200 & 5 & 9 & 442 & \\
60 & 200 & 5 & 10 & 481 & 5.8
\end{tabular}

(1)

23

$\begin{array}{lllll}62 & 200 & 6 & 2 & 97\end{array}$

$\begin{array}{lllll}63 & 200 & 6 & 3 & 235\end{array}$

$\begin{array}{lllll}64 & 200 & 6 & 4 & 392\end{array}$

$\begin{array}{lllll}65 & 200 & 6 & 5 & 476\end{array}$

$\begin{array}{lllll}66 & 200 & 6 & 6 & 548\end{array}$

$\begin{array}{lllll}67 & 200 & 6 & 7 & 626\end{array}$

$\begin{array}{lllll}68 & 200 & 6 & 8 & 676\end{array}$

$\begin{array}{lllll}69 & 200 & 6 & 9 & 739\end{array}$

$\begin{array}{lllll}70 & 200 & 6 & 10 & 792\end{array}$

6.4

$\begin{array}{lllll}71^{*} & 200 & 7 & 1 & 32\end{array}$

$\begin{array}{lllll}72 & 200 & 7 & 2 & 119\end{array}$

$\begin{array}{lllll}73 & 200 & 7 & 3 & 296\end{array}$

$\begin{array}{lllll}74 & 200 & 7 & 4 & 459\end{array}$

$\begin{array}{lllll}75 & 200 & 7 & 5 & 554\end{array}$

$\begin{array}{lllll}76 & 200 & 7 & 6 & 661\end{array}$

$\begin{array}{lllll}77 & 200 & 7 & 7 & 776\end{array}$

$\begin{array}{lllll}78 & 200 & 7 & 8 & 872\end{array}$

$\begin{array}{lllll}79 & 200 & 7 & 9 & 947\end{array}$

$\begin{array}{lllll}80 & 200 & 7 & 10 & 1046\end{array}$

7.3

$81^{*} 200 \quad 8 \quad 1 \quad 25$

$\begin{array}{lllll}82 & 200 & 8 & 2 & 97\end{array}$

$\begin{array}{lllll}83 & 200 & 8 & 3 & 231\end{array}$

$\begin{array}{lllll}84 & 200 & 8 & 4 & 395\end{array}$

$\begin{array}{lllll}85 & 200 & 8 & 5 & 494\end{array}$

$\begin{array}{lllll}86 & 200 & 8 & 6 & 575\end{array}$

$\begin{array}{lllll}87 & 200 & 8 & 7 & 666\end{array}$

$\begin{array}{lllll}88 & 200 & 8 & 8 & 768\end{array}$

$\begin{array}{lllll}89 & 200 & 8 & 9 & 846\end{array}$

$\begin{array}{lllll}90 & 200 & 8 & 10 & 921\end{array}$

$91^{*} 200 \quad 9 \quad 1 \quad 5$

$\begin{array}{lllll}92 & 200 & 9 & 2 & 87\end{array}$

$\begin{array}{lllll}93 & 200 & 9 & 3 & 189\end{array}$

$\begin{array}{lllll}94 & 200 & 9 & 4 & 285\end{array}$

$\begin{array}{lllll}95 & 200 & 9 & 5 & 350\end{array}$

$\begin{array}{lllll}96 & 200 & 9 & 6 & 422\end{array}$

$\begin{array}{lllll}97 & 200 & 9 & 7 & 516\end{array}$

$\begin{array}{lllll}98 & 200 & 9 & 8 & 576\end{array}$

$\begin{array}{lllll}99 & 200 & 9 & 9 & 629\end{array}$

$\begin{array}{lllll}100 & 200 & 9 & 10 & 696\end{array}$

696

* Number of unused experiment runs

7.9

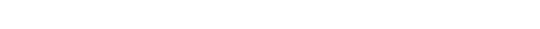


The residual plots (Normal probability plot, Residuals versus fitted values, Residuals vs observed order of fitted values and the histogram of the frequency of the residuals) obtained from the analysis is displayed in Figure 3 while the corresponding estimated regression coefficients are deferred in Table 2 . The equations obtained from log-linear regression analysis which show the influence of $\mathrm{pH}$, mass, retention time on the yield and is corresponding reduced form are presented in equations (3) and (4). It should be noted that yield values for the first day (Day 1 ) were not employed in the development of the model. This action was necessary so as to allow for consistent biogas yield from the experiments.

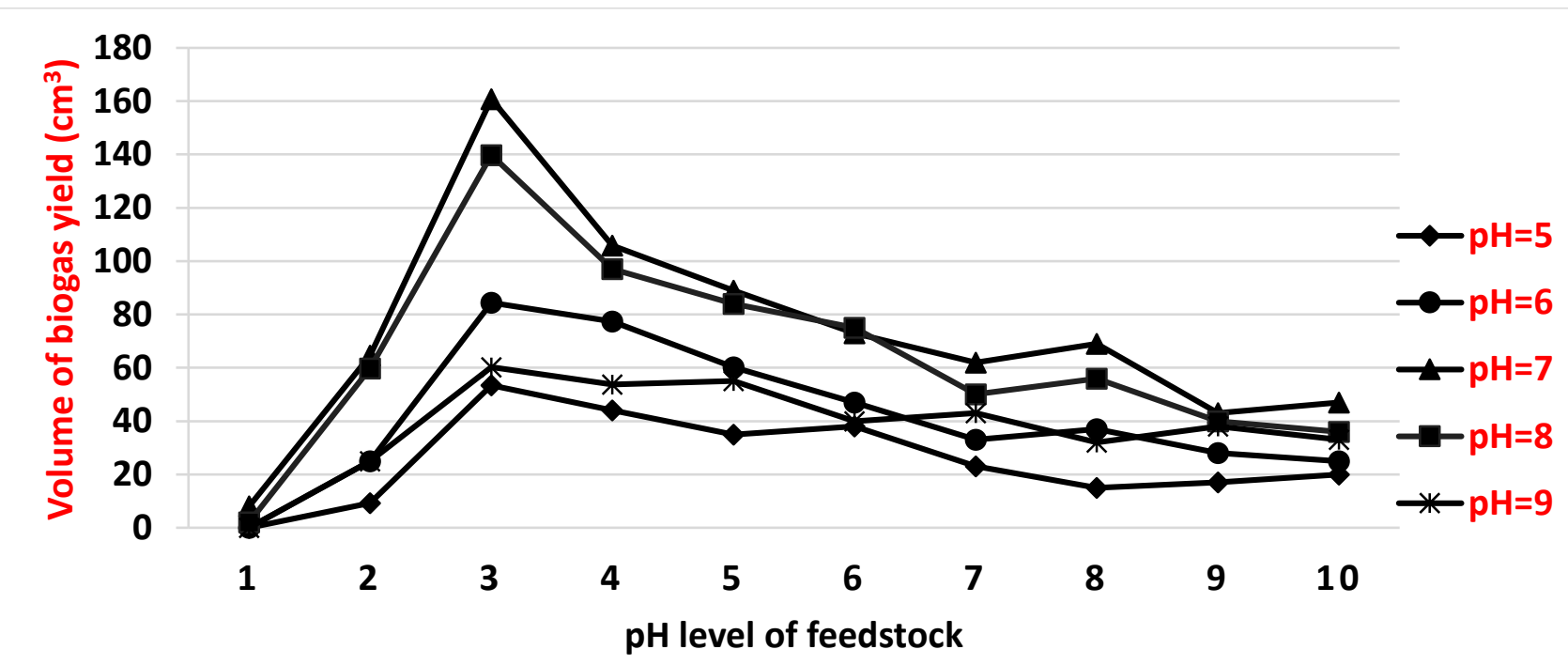

Fig. 1: Daily biogas yield from $100 \mathrm{~g}$ of poultry droppings for digesters at different pH conditions

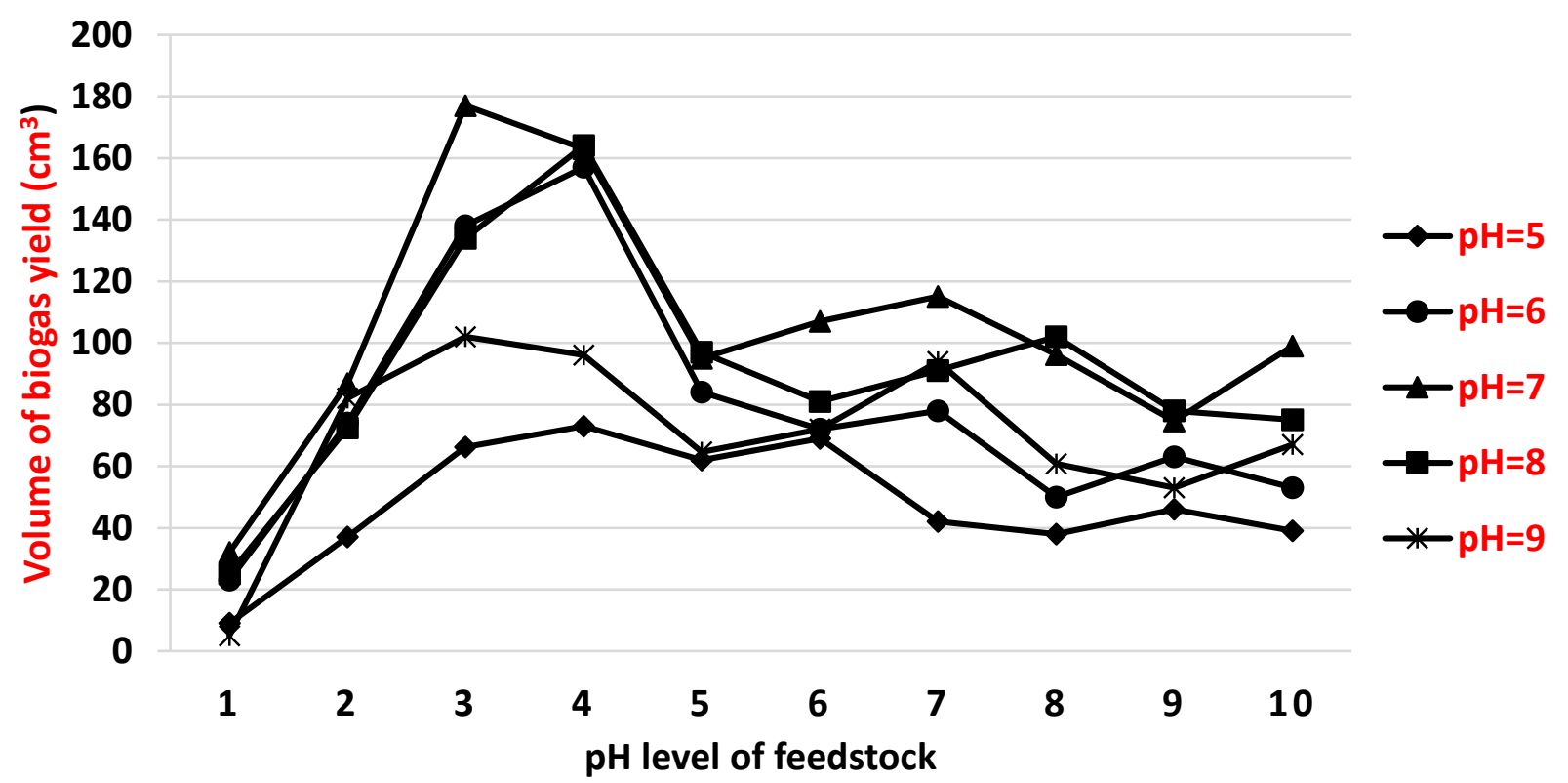

Fig. 2: Daily biogas yield from $200 \mathrm{~g}$ of poultry droppings for digesters at different pH conditions. 

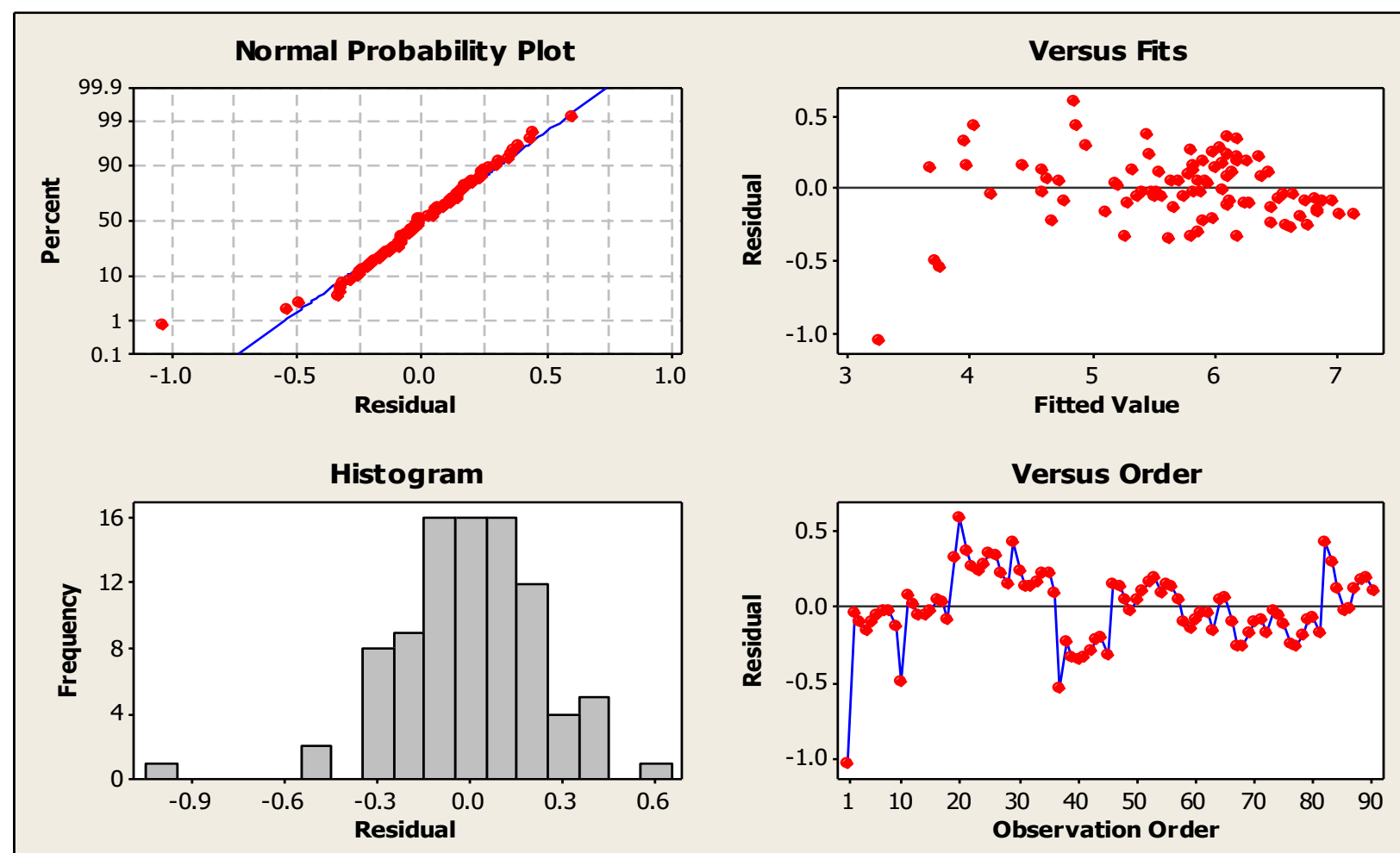

Fig. 3: Residual plots for the biogas yield obtained from poultry droppings at different $\mathrm{pH}$ values

Table 2: Regression coefficients for the reduced biogas yield analysis

\begin{tabular}{cccccc}
\hline & Predictor & Coefficient & Coefficient of Squared Effects & Students T-Test Value & P Value \\
\hline 1 & Constant & -1.0025 & 0.5347 & -1.87 & 0.064 \\
2 & $X_{1}$ & 0.1626 & 0.0584 & 2.78 & 0.007 \\
3 & $X_{2}$ & -0.0428 & 0.0053 & -8.02 & 0.000 \\
4 & $X_{3}$ & 1.9945 & 0.2071 & 9.63 & 0.000 \\
5 & $X_{1} X_{2}$ & 0.0148 & 0.0014 & 10.36 & 0.000 \\
6 & $X_{3}^{2}$ & -0.2623 & 0.0376 & -6.97 & 0.000 \\
7 & $X_{1}^{2} X_{2}$ & -0.0011 & $-9.8770 \times 10^{-5}$ & -10.99 & 0.000 \\
8 & $X_{3}^{3}$ & 0.0117 & 0.0021 & 5.65 & 0.000 \\
\hline
\end{tabular}

Prediction Precision Parameters

$\mathrm{S}=0.247919, \quad \mathrm{R}-\mathrm{Sq}=92.8 \%, \quad \mathrm{R}-\mathrm{Sq}(\mathrm{adj})=92.1 \%, \mathrm{MAPE}=19.97$

$$
\begin{aligned}
& \ln \left(Y_{i}\right)=-15.9+3.50 X_{1 i}+0.0544 X_{2 i}+2.98 X_{3 i}-0.056 X_{1 i}^{2} \\
& -0.0129 X_{1 i} X_{2 i}-0.198 X_{1 i} X_{3 i}-0.001 X_{2 i} X_{3 i}-0.292 X_{3 i}^{2} \\
& -0.0153 X_{1 i}^{3}+0.0009 X_{1 i}^{2} X_{2 i}+0.0001 X_{1 i} X_{2 i} X_{3 i}+0.0089 X_{1 i}^{2} X_{3 i} \\
& +0.0042 X_{1 i} X_{3 i}^{2}+0.0117 X_{3 i}^{3} \\
& \quad \ln \left(Y_{i}\right)=-1.00+0.163 X_{1 i}-0.0428 X_{2 i}+1.99 X_{3 i}+0.0148 X_{1 i} X_{2 i} \\
& -0.262 X_{3 i}^{2}-0.00109 X_{1 i}^{2} X_{2 i}+0.0117 X_{3 i}^{3}
\end{aligned}
$$

It was generally observed from the outcome of each run of the experiment that the terminating $\mathrm{pH}$ generally inclined or declined (as the case may be) from their respective starting $\mathrm{pH}$ to terminating $\mathrm{pH}$ range between 6.0 and 8.0. This observation is similar to the finding in Kheiredine et al. [9] and indicates that in situations of uncontrolled anaerobic digestions, the $\mathrm{pH}$ tends to swing towards neutrality 
after substrate incubation. The effect of this is that for biogas reactions that have starting $\mathrm{pH}$ values far away from 7.0, there is likelihood that there may be a delay in favourable biogas yield even in the face of longer retention times until $\mathrm{pH}$ that is positive to digestion is attained. The effect of different values of starting $\mathrm{pH}$ can also be observed in Figures 1 and 2, which clearly shows that substrates with initial $\mathrm{pH} 7$, $8,6,9,5$ performed better in terms of the order of increasing biogas yield especially between the retention ranges of day 2 to day 8 . Clearly, this indicates that starting $\mathrm{pH}$ that tends towards neutral possess the potential to produce better biogas yield. With respect to the cumulative biogas yield for $100 \mathrm{~g}$ and $200 \mathrm{~g}$ of substrate obtained at the end of day 10 (Table 1), $\mathrm{pH}=7$ produced the highest (722 and $\left.1046 \mathrm{~cm}^{3}\right)$, followed by $\mathrm{pH}=8\left(640\right.$ and $\left.921 \mathrm{~cm}^{3}\right)$, $\mathrm{pH}=6\left(417\right.$ and $\left.792 \mathrm{~cm}^{3}\right), \mathrm{pH}=9\left(346\right.$ and $\left.696 \mathrm{~cm}^{3}\right)$ and $\mathrm{pH}=5\left(255\right.$ and $\left.481 \mathrm{~cm}^{3}\right)$. Given that the starting masses and $A D$ conditions of the substrates were the same, the implication of the result is that $\mathrm{pH}=7$ is the ideal condition for starting $A D$ processes for poultry droppings substrate.

In further investigating the influence of $\mathrm{pH}$ alongside mass and retention time independent factors, the outcome of the full regression analysis using the loglinear relation $\{$ Equation (3) $\}$ indicated that the $\mathrm{pH}$, mass and retention time exhibited main effects on biogas yield. In addition, multiple effects of interactions among the independent factors were also observed. Such interactions included quadratic and cubic level interactions of $\mathrm{pH}$ with mass $\left(X_{1 i} X_{2 i}, X_{1 i}^{2} X_{2 i}\right), \mathrm{pH}$ with and retention time $\left(X_{1 i} X_{3 i}, X_{1 i}^{2} X_{3 i}, X_{1 i} X_{3 i}^{2}\right)$ as well as with both mass and retention time $\left(X_{1 i} X_{2 i} X_{3 i}\right)$. However, some of the interactions were observed to be non-significant as their $p$ values existed above the expected threshold of 0.05 . Consequently, the rerun of the significant predictor variables yielded equation (4). As can be observed in Table 2, all the predictor variables of the biogas yield obtained from the reduced equation were significant. pH exhibited linear effect, as well as quadratic and cubic interaction effect with mass in influencing biogas yield.

Furthermore, the value of $92.8 \%$ obtained for the RSquare precision parameter implies a strong relationship between the biogas yield and its linear, quadratic and cubic predictor variables. Also, the adjusted R-square value of $92.1 \%$ obtained (Table 2 ), indicates that a high degree of variability in the response was captured and explained by the reduced model. In addition, the standard error of regression $(S)$ of about 0.25 indicates a high precision accuracy of the prediction model as this value indicate that the predicted values lie within the desired $95 \%$ prediction interval. From the residual plot (Figure 3 ) it can be observed that the probability plot of the predictions exhibits approximately normal distribution characteristics and the residuals versus fits plot demonstrate a random residual distribution. However, the residual versus order plot seems to indicate cyclic influences in the model. The cause for this behaviour was not investigated as the study was primarily focused on the effect of $\mathrm{pH}$, mass and retention time on the biogas yield.

The MAPE of the reversed logarithmic values of the predicted biogas values was obtained as 19.97 (Table 2). This result indicates that the model showed a good prediction of the biogas yield. This result is in line with the MAPE evaluation measure proposed by [32].

\section{CONCLUSION}

An investigation to determine effect of $\mathrm{pH}$ on biogas yield obtained from poultry droppings using an experimental design approach has been undertaken. From the results, it was concluded that $\mathrm{pH}$, mass of substrate and retention time exhibit statistically significant main effect as well as quadratic and cubic interaction effects on biogas yield. Also, the maximum yield of gas generated using $100 \mathrm{~g}$ and $200 \mathrm{~g}$ occurred when the $\mathrm{pH}$ was set to 7 . Furthermore, it was concluded, that factorial design can be employed in estimation of biogas yield from poultry droppings.

\section{CORRESPONDENCE}

All correspondence should be sent to O.A. Adebimpe, Department of Industrial and Production Engineering, University of Ibadan, Nigeria, e-mail: oa.adebimpe@mail1.ui.edu.ng.

\section{REFERENCES}

[1]. Weiland, P. "Biogas production: current state and perspectives", Applied Microbiology and Biotechnology, Vol. 85, Number 4, 2010, pp. 849-860.

[2]. de Souza, S. N., Santos, R. F. and Fracaro, G. $P$. "Potential for the production of biogas in alcohol and sugar cane plants for use in urban buses in the Brazil", World Renewable Energy 
Congress, Sweden, May 8-13, 2011, pp. 418424.

[3]. Pazuch, F. A., Nogueira, C. E. C., Souza, S. N. M., Micuanski, V. C., Friedrich, L. and Lenz, A. M. "Economic evaluation of the replacement of sugar cane bagasse by vinasse, as a source of energy in a power plant in the state of Paraná, Brazil", Renewable and Sustainable Energy Review, Vol. 76, Number C, 2017, pp. 34-42.

[4]. Rao, P. V., Baral, S. S., Dey, R. and Mutnuri, S. "Biogas generation potential by anaerobic digestion for sustainable energy development in India", Renewable and Sustainable Energy Review, Vol. 14, Number 7, 2010, pp. 20862094.

[5]. Barrera, E. L., Spanjers, H. Dewulf, J., Romero, O. and Rosa, E. "The sulfur chain in biogas production from sulphate rich liquid substrates: a review on dynamic modeling with vinasse as model substrate", Journal of Chemical Technology and Biotechnology, Vol. 88, 2013, pp. $1405-1420$.

[6]. Panwar, N. L., Kaushik, S. C. and Kothari, S. "Role of renewable energy sources in environmental protection: A review", Renewable and sustainable energy reviews, Vol. 15, Number 3, 2011, pp. 1513-1524.

[7]. Scarlat, N., Dallemand, J-F. and Fahl, F. "Biogas: Developments and perspectives in Europe", Renewable Energy, Vol. 129, Part A, 2018, pp. 457-472.

[8]. Poeschl, M., Ward, S. and P. Owende. "Environmental impacts of biogas deploymentPart II: life cycle assessment of multiple production and utilization pathways", Journal of Cleaner Production, Vol. 24, Number 10, 2012, pp. 184-201.

[9]. Kheiredine, B., Derbal, K. and BencheikhLehocine, M. "Effect of starting $\mathrm{pH}$ on the produced methane from dairy wastewater in thermophilic phase", Chemical Engineering, Vol. 38, 2014, pp. 511-516.

[10]. Achinas, S., Achinas, V. and Euverink G. J. W. "A technological overview of biogas production from biowaste", Engineering, Vol. 3, Number 3, 2017, pp. 299-307.

[11]. Ngumah, C. C., Ogbulie, J. N., Orji, J. C., and Amadi, E. S. "Biogas potential of organic waste in Nigeria", Journal of Urban and Environmental Engineering, Vol. 7, Number 1, 2013, pp. 110-116.

[12]. Zain, M. M. and Mohamed, A. R. "An overview on conversion technologies to produce value added products from $\mathrm{CH}_{4}$ and $\mathrm{CO}_{2}$ as major biogas constituents", Renewable and Sustainable Energy Reviews, Vol. 98, 2018, pp. 56-63.

[13]. Bharathiraja, B., Sudharsana, T., Jayamuthunagai, J., Praveenkumar, R., Chozhavendhan, S., and Iyyappan, J. "Biogas production-A review on composition, fuel properties, feed stock and principles of anaerobic digestion", Renewable and Sustainable Energy Review, Vol. 90, 2018, pp. 570-582.

https://doi.org/10.1016/j.rser.2018.03.093.

[14]. Haryanto, A., Triyono, S., and Wicaksono, N. H. "Effect of Hydraulic Retention Time on Biogas Production from Cow Dung in a Semi Continuous Anaerobic Digester", International Journal of Renewable Energy Development, Vol. 7, Number 2, 2018, pp. 93-100.

[15]. Burke, D. A. Dairy Waste Anaerobic Digestion Handbook, Environmental Energy Company, 6007 Hill Street Olympia, WA 98516, 2001.

[16]. Sawyerr, N., Trois, C., Workneh, T. and Okudoh, V. "An Overview of Biogas Production: Fundamentals, Applications and Future Research", International Journal of Energy Economics and Policy, Vol. 9, Number 2, 2019, pp. 105-116.

[17]. Dennis, O. E. "Effect of Innoculum on biogas yield", Journal of Applied Chemistry, Vol. 8, Number 2, 2015, pp. 5-8.

[18]. Chukwuma, E. C., Chukwuma, G. C., Orakwe, L. C. and Odoh, C. C., "Mesophilic co-digestion of cattle paunch with poultry digestion of cattle paunch with poultry digestion: mixture effect assessment on biogas production potentials", Nigerian Journal of Technology, Vol. 32, Number 2, 2013, pp. 556-560.

[19]. Van Foreest, F. Perspectives for biogas in Europe, Oxford, UK: Oxford Institute for Energy Studies; 2012.

[20]. Parsaee, M., Kiani, M. K. D. and Karimi, K. "A review of biogas production from sugarcane vinasse", Biomass and bioenergy, Vol. 122, 2019, pp. 117-125.

[21]. Sorathia, H. S., Rathod, P. P., and Sorathiya, A. $S$. "Biogas generation and factors affecting the Bio-gas generation-a review study", International Journal of Advanced Engineering Technology, Vol. 3, Number 3, 2012, pp. 7278.

[22]. Sivakumar, P., Bhagiyalakshmi, M. and Anbarasu, K. "Anaerobic treatment of spoiled 
milk from milk processing industry for energy recovery-A laboratory to pilot scale study", Fuel, Vol. 96, 2012, pp. 482-486.

[23]. Paramaguru, G., Kannan, M. and Lawrence, P. "Effect of pH on Biogas Production through Anaerobic Digestion of Food Waste", Journal of Advanced Engineering Research, Vol. 4, Number 1, 2017, pp. 59-62.

[24]. Belostotskiy, D., Jacobi, H. F., Strach, K. and Liebetrau, J. "Anaerobic digestion of chicken manure as a single substrate by control of ammonia concentration", AD13 Recovering (bio) Resources for the World, 2013.

[25]. Kim, J. K. "Effects of temperature and hydraulic retention time on anaerobic digestion of food waste", Journal of Bioscience and Bioengineering, Vol. 102, Number 4, 2006, pp. 328-323. https://doi.org/10.1263/jbb.102.328.

[26]. Budiyono, I. W. "Increasing biogas production rate from cattle manure using rumen fluid as inoculums", International Journal of Basic \& Applied Sciences, Vol. 23, 2010, pp. 41-47.

[27]. Raheman, H. and Mondal, S. "Biogas production potential of jatropha seed cake", Biomass and Bioenergy, Vol. 37, 2012, pp. 2530.
[28]. Kafle, G. K., Bhattarai, S., Kim, S. H. and Chen, L. "Anaerobic digestion of Chinese cabbage waste silage with swine manure for biogas production: batch and continuous study", Environmental Technology, Vol. 35, 2014, pp. 2708-2717.

[29]. Jayaraj. S, Deepanraj, B and Sivasubramanian, V. "Study on the effect of $\mathrm{pH}$ on biogas production from food waste by anaerobic digestion", $g^{\text {th }}$ International Green Energy Conference, National Institute of Technology, Calicut-673601, India, May 2014, pp. 799-805.

[30]. Deepanraj, B., Sivasubramanian, V. and Jayaraj, S. "Kinetic study on the effect of temperature on biogas production using a lab scale batch reactor", Ecotoxicology and Environmental Safety, Vol. 121, 2015, pp. 100104.

https://doi.org/10.1016/j.ecoenv.2015.04.051

[31]. Jørgensen, P. J. 2009. Biogas- Green Energy, Process, Design, Energy Supply, \& Environment, Digisource Books, Denmark, 2009.

[32]. Lewis, C. D. Industrial and business forecasting methods, London, 1982. 